\title{
Case Study on Manufacturing Technology Transfer and Implementation
}

\author{
Heekyung $\mathrm{An}^{*}$ \\ Korea Institute of Industrial Technology/Daegu, Republic of Korea. \\ * Corresponding author. Tel.: +82535800149; email: ruth@kitech.re.kr \\ Manuscript submitted March 29, 2017; accepted April 25, 2017. \\ doi: 10.17706/ijeeee.2018.8.2.112-121
}

\begin{abstract}
This study deals with organizational cases related to the transfer and implementation of manufacturing technology in Korea. The Korea Institute of Industrial Technology (KITECH) was founded to foster innovation in SMEs through the development and commercialization of optimized manufacturing technologies suitable for the manufacturing sites of various enterprises. The Institute has, so far, established ten regional divisions and fifty centers across the country for closer support for enterprises based in different regions. This study analyzed the management case of Daegyeong Regional Division (DRD), which is part of the organization, and suggested a model for the transfer and implementation of manufacturing technology. First, the management case of the DRD was introduced, and subsequently, the analysis results of the management and outcomes of technology transfer and implementation were suggested. For the suggested outcomes of the technology transfer and implementation to be objective, a survey was conducted in cooperation with a third-party expert survey organization. Seventy-three companies, which benefited from the technology transfer between 2009 and 2013, when the DRD was established, were surveyed. The survey results were analyzed by comparing the economic outcomes before and after the given support.
\end{abstract}

Key words: Manufacturing technology, technology transfer, commercialization, stakeholder, infrastructure.

\section{Introduction}

The purpose of manufacturing technology development is to change the form, state, or relationship between materials and products, to improve the manufacturing process, and to foster innovation in the automation system, in order to achieve greater utility and value in an industry. Manufacturing enterprises apply technologies with such enhanced effectiveness and efficiency to manufacturing, thereby, further escalating competitiveness [1], [2]. However, unlike a few large-scale manufacturing enterprises, the majority of SMEs have not developed their own technologies that can be applied on site. Therefore, in pursuing innovation and improving the manufacturing infrastructure of these companies, cooperating with research institutions is inevitable. Numerous researchers have suggested that for manufacturing companies to promote technological innovation and derive profits, cooperating with research institutions is highly fundamental [3]-[7].

The Korean government has founded and been leading 25 government-funded research institutions headed by the National Research Council of Science and Technology, aiming at the technological innovation of industries. Among these 25 research institutions is KITECH, which was founded in 1989 with the purpose of leading innovation manufacturing technology and capacity enhancement of SMEs, which constitute over $99 \%$ of industries. While other research institutions focus on the development of basic technologies, 
KITECH offers the following three major functions: 1) the development of original industrial technologies for manufacturing, 2) commercialization of developed technologies, and 3) technological support to and distribution of outcomes of SMEs. In order to develop original industrial technologies that SMEs, the major technology consumers, need and to apply them to their manufacturing sites, it is necessary to diagnose the condition of each company. This is because each company has varied requirements and ranges of application for technologies according to its organization, management, manufacturing line, and culture [8]. To help such companies continue growing, it is necessary to create further a network of experts engaged in related fields to provide full-cycle technological support. As for technological problems, which occur frequently in the process of product manufacturing, direct interventions by experts should be available to solve them and to complete the transfer and implementation of manufacturing technologies. In order to develop, transfer, and implement technologies optimized for target consumers, field-optimized support should be available in close proximity. To this end, KITECH established ten regional divisions at industrial clusters or selected sites in preparation for future industrial clustering across the nation, and has been managing them to facilitate contact with consumers and provide real-time technological support. The regional divisions installed at various regions reflect the demand of each region. Each has installed and runs its separate research and development (R\&D) and technological center; these attached centers total 50. In order for these regional divisions and technological centers to successfully serve their functions and roles, the identification of key stakeholders and establishment of strategies and plans reflecting these expert resources should be prioritized. This study aims to suggest a model for the transfer and implementation of industrial manufacturing technology. To this end, the case of the KITECH DRD, which specializes in development of manufacturing technologies and technology transfer in Korea, was analyzed. By demonstrating the infrastructure and management technology of the DRD, a model for practical industrial transfer and implementation of manufacturing technology was proposed. The responses of the industries that benefited from the support were surveyed, the effectiveness of the model was analyzed, and the outcomes were suggested.

\section{Methods}

The case study was conducted through two processes. First, the analysis of the DRD management case was demonstrated to suggest our model for the transfer and implementation of manufacturing technology. In order to ensure continued promotion of technology development and industrial transfer, it is necessary to first identify the stakeholders in technology development and transfer, and to form a healthy network of these parties [9]-[12]. In this study, stakeholders were categorized into three groups, namely, company, client, and cooperation partner. The company comprises the KITECH headquarters and the DRD, the client base comprises the industries based in the Daegu-Gyeongbuk region, and the cooperation partners include the central and local governments, which establish and implement industrial policies. There are various other types of stakeholders including universities, other research institutions, and the general public; however, these were excluded from this study. The overview of the categorized stakeholders was identified, and the DRD was founded in May, 2009, referring to the identified results. The division has established an entity and is now running an organization. Chapter III demonstrates the model for the transfer and implementation of manufacturing technology, reflecting the characteristics of these stakeholders.

Second, the effectiveness of the DRD management case was analyzed. The survey for effectiveness analysis was conducted through a third-party institution to ensure its objectivity. The effectiveness was demonstrated through the outcome analysis following the investment. Investment is the amount spent on the establishment of infrastructure, R\&D, and short-term technological support. For investment, the data from the DRD, collected between May 2009 and December 2013, was used. The outcomes following the 
investment were evaluated through the survey of the 73 companies that had received the benefits of technology development and transfer by the DRD between May 2009 and December 2013. The survey period was between April and May 2014, and the responses were received through the telephone and email. Survey questions consisted of four parts concerning the general overview of companies, R\&D and outcomes, ripple effect, and diagnosis, among which, the questions used for this study were limited to only some of those concerning R\&D and outcomes. Sales, cost reduction, import-substitution effect, and new employment overview before and after the support program were analyzed. Economic outcomes expected from companies were analyzed by comparing them with invested resources, and the effect of technology transfer and implementation according to the management of DRD was briefly presented.

\section{Model for Transfer and Implementation of Manufacturing Technology}

\subsection{Stakeholder Overview}

Table 1. Composition and Effect of Stakeholders

\begin{tabular}{|c|c|c|}
\hline Category & Stakeholder & Effect \\
\hline \multirow[t]{2}{*}{ Company } & $\begin{array}{l}\text { KITECH } \\
\text { Headquarters }\end{array}$ & $\begin{array}{l}\text { Selecting areas of } \\
\text { manufacturing technology } \\
\text { and defining the range of } \\
\text { role }\end{array}$ \\
\hline & DRD & $\begin{array}{l}\text { Manufacturing technology } \\
\text { provider for the } \\
\text { Daegu-Gyeongbuk region }\end{array}$ \\
\hline \multirow{2}{*}{$\begin{array}{l}\text { Cooperatio } \\
\text { n partner }\end{array}$} & $\begin{array}{l}\text { Central } \\
\text { government }\end{array}$ & $\begin{array}{l}\text { Establishing national } \\
\text { industrial policies and } \\
\text { infrastructure, and } \\
\text { introducing the R\&D } \\
\text { budget }\end{array}$ \\
\hline & $\begin{array}{l}\text { Local } \\
\text { government }\end{array}$ & $\begin{array}{l}\text { Establishing regional } \\
\text { industrial policies and } \\
\text { infrastructure, and } \\
\text { introducing the R\&D } \\
\text { budget }\end{array}$ \\
\hline Client & $\begin{array}{l}\text { Manufacturing } \\
\text { companies in } \\
\text { the } \\
\text { Daegu-Gyeong } \\
\text { buk region }\end{array}$ & $\begin{array}{l}\text { Beneficiary of } \\
\text { manufacturing technology }\end{array}$ \\
\hline
\end{tabular}

Table I shows the stakeholders related to the transfer and implementation of manufacturing technology. The stakeholders were categorized into three types and the company comprises the KITECH headquarters and the DRD. The KITECH headquarters directs approximately 50 organizations based across the nation, and defines the areas of manufacturing technology and the extent of roles for the entire organization. The areas of manufacturing technology set by the KITECH mainly consist of the three areas (advanced manufacturing technology, sustainable manufacturing system, and industrial technology convergence). Advanced manufacturing technology includes casting, molds and dies, materials processing, welding, heat treatment, and surface treatment. These are the core processing technology areas that are essential for converting raw materials into materials, and materials into parts. Sustainable manufacturing system addresses resource reduction, energy efficiency enhancement, and process optimization, while also ensuring the sustainability of the manufacturing system. The main objectives of this area are to develop and transfer systems that consume lesser resources in the manufacturing process and enhance manufacturing 
efficiency concurrently. Industrial technology convergence is an applied technology area that upgrades existing technologies, through the convergence of different technologies, and creates new markets by discovering future growth engines. All the organizations under KITECH conduct technology development with the above three areas as their scope and aim to transfer new technologies to companies working in the region. Therefore, the DRD should perform R\&D focusing on these three areas in accordance with the regional industrial overview and support the local companies accordingly.

In order to facilitate R\&D and technology transfer, it is essential to consider the needs of cooperation partners. The government-funded research institution, KITECH, is run from the budget provided by the government, and has been pushing $R \& D$ activity forward. In order to make sure that government-funded research institutions are able to execute and continue very in-depth $R \& D$, government policies and budgetary support are very critical [13], [14]. Thus, it is important to properly reflect government policies to set the direction of R\&D. The Korean government has been implementing the Manufacturing Innovation Strategy 3.0 based on Industry 4.0, aiming at capacity enhancement of the current manufacturing companies. The main contents of the Manufacturing Innovation Strategy 3.0 mainly include the expansion of smart manufacturing methods, creation of new industries representing the creative economy, and smart innovation of regional manufacturing industries. To achieve this, a smart manufacturing R\&D roadmap has been published, and the government has been inducing the development of the big eight smart manufacturing technologies by 2020 , including real-time monitoring technology through smart sensors, deep-learning robot technology, demand-optimized design technology, and plant facility digitalization technology. Sometimes, KITECH selects R\&D items according to the governmental R\&D policy directions; however, it has been mainly investing its efforts in founding regional organizations and the regional transferring of manufacturing technologies, in response to the requests of various local governments. The management directions of the DRD, thus, have been set, and its sub-organization has been formed according to the industrial policies and direction of the local government. The Daegu-Gyeongbuk region, supported by the DRD, houses the local governments of the Daegu Metropolitan City and the Gyeongsangbuk-do Province. According to the Regional Development Plan of the government, the Daegu Metropolitan City, with 2.5 million inhabitants, is designing plans to establish a leading city of future automotive industry, global medical industry hub, and fostering future industries related to the internet of things. The Gyeongsangbuk-do Province is home to 2.7 million inhabitants, and is actively inviting companies with positive prospects and promising employment effects in the fields of IT, aero industries, auto parts, and leisure services. Additionally, it is aiming to elevate its industries to a higher level with a strategic focus on carbon fiber and 3D printing. The province is also planning to strategically foster ICT convergence, robot, energy, and state-of-the-art medical and bio industries. The DRD is responsible, not only for providing technological support corresponding to the characteristics of the industrial clusters of the Daegu-Gyeongbuk region, but also for discovering new industries for the future and executing projects to establish infrastructure for selected sites for industrial clustering.

The main actors in manufacturing technology are manufacturing companies that apply and implement these technologies. Manufacturing companies are the direct beneficiaries of technologies developed by research institutions; therefore, it is absolutely crucial to have an overview of manufacturing industries, which make up the infrastructure of regional industries, and to develop and transfer technologies that can be the major engine for future growth of enterprises as well as those demanded by enterprises. In particular, public R\&D projects should focus on technological support for the manufacturing innovation of SMEs [15]. The manufacturing industry of the Daegu region accounts for $23.4 \%$ of the entire Korean manufacturing industry in terms of gross regional product. In the manufacturing industry, the products by manufacturing enterprise type consist of $21.1 \%$ cars and trailers, $13.9 \%$ machine and equipment, and $13.7 \%$ processed 
metal products. The manufacturing industry of the Gyeongsangbuk-do province makes up $51.1 \%$ of all industries in terms of gross regional domestic product. Assuming the manufacturing industry as $100 \%$, the product by manufacturing enterprise type consists of $37.8 \%$ electronic parts, and $21.6 \%$ primary metal processing. Therefore, manufacturing technology support is required for the existing industrial clusters of manufacturing fields such as automotive, trailer, machine and equipment, processed metal product, and electronic parts. As for selected sites for industrial clustering, manufacturing technology support will be in need for technologies related to aero, construction equipment, biomedical, and 3D printing industries, according to the industrial policy direction of the local government.

\subsection{Model for the Transfer and Implementation of Manufacturing Technology: The DRD Management Case}

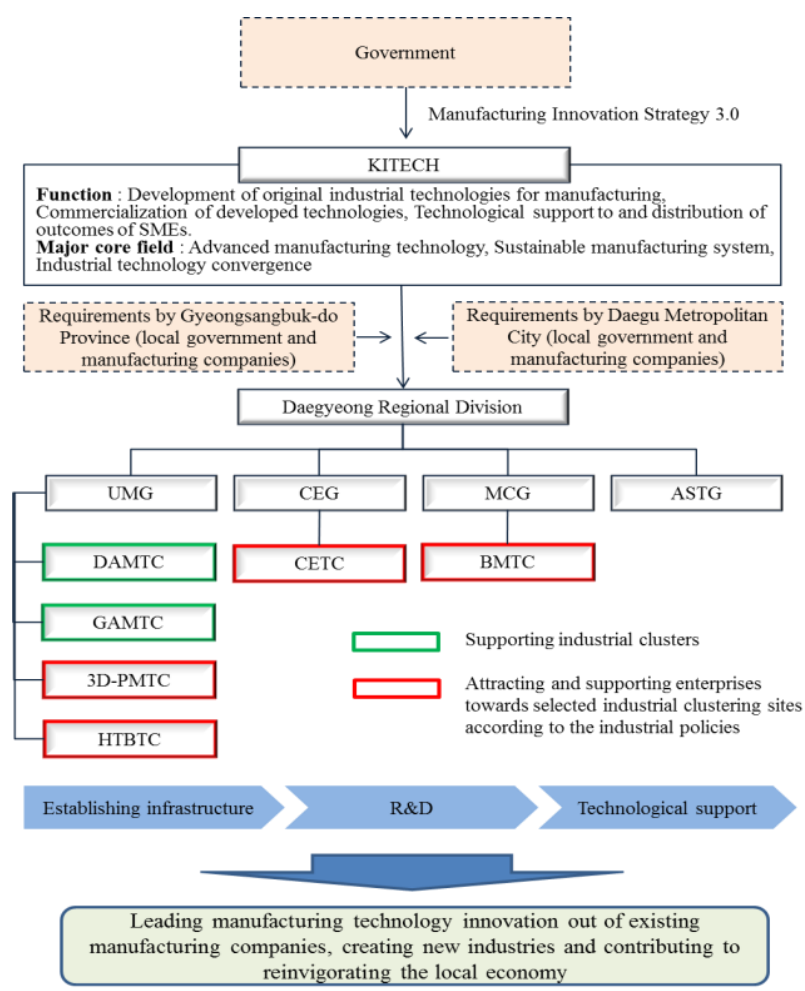

Fig. 1. Model for the transfer and implementation of manufacturing technology of the DRD.

The model for the transfer and implementation of manufacturing technology of the DRD was designed to reflect the previously discussed overview of stakeholders (Fig. 1). The organizational structure and management of the DRD focused on the role and strategic areas of the headquarters. Successively, the role and strategic areas of the headquarters are based on the Manufacturing Innovation Strategy 3.0 of the government, and are managed by the government in accordance with the purpose of infrastructure. The DRD, which was founded to provide optimized support for regional SMEs and induce their manufacturing innovation, organized four final groups reflecting the areas requested by the Daegu Metropolitan City and the Gyeongsangbuk-do Province, as well as the governmental R\&D direction and the roles and areas required by the headquarters. In this manner, the division performs infrastructure building, technology development, and technology transfer tasks. The Ultimate Manufacturing R\&D Group (UMG) develops and commercializes diverse original technologies that allow ultimate manufacturing in ultra-high temperature, ultra-high pressure, and high vibration conditions. The group's ultimate objective is to develop highly advanced processing technologies required in the real fields of all manufacturing industries and transfer 
them to enterprises. The UMG houses the Daegu Advanced Manufacturing Technology Support Center (DAMTC), Goryeong Advanced Manufacturing Technology Support Center (GAMTC), High-Tech Bearing Technology Center (HTBTC), and 3D Printing Manufacturing Technology Center (3D-PMTC) under its supervision. The Construction Equipment R\&D Group (CEG) establishes the infrastructure related to intelligent construction equipment parts based on IT convergence technologies, and develops and transfers practical technologies. The group builds the infrastructure, and performs technology development and extends enterprise support around the Gyeongsan city of the Gyeongsangbuk-do Province with the objective of import substitution of core parts for construction equipment. There is a Construction Equipment Technology Center (CETC) within the group. The Mechatronics Convergence R\&D Group (MCG) is dedicated to developing human-friendly mechatronic technologies and strategic biomedical technologies. The Biomedical Manufacturing Technology Center (BMTC) within the group is responsible for the latter. This center was installed according to the plan by the Gyeongsangbuk-do Province to foster advanced medical and bio industries. The Aircraft System Technology Group (ASTG) was also installed according to the aero industry promotion plan by the Gyeongsangbuk-do Province. This group is dedicated to building the infrastructure for aero electric testing and assessment, and the development and commercialization of domestic aero parts and electronic system technologies. Two aspects mainly characterize the organization of the DRD. First, it supports industrial clusters and leads manufacturing technology innovation out of existing manufacturing companies. The Daegu Advanced Manufacturing Technology Support Center and Goryeong Advanced Manufacturing Technology Support Center of the Ultimate Manufacturing R\&D Group are good examples. These centers have been providing the existing companies processing metals and manufacturing auto parts, electronic parts, and machines based in Daegu and Gyeongsangbuk-do Province with advanced manufacturing technologies and sustainable manufacturing system areas defined by the KITECH headquarters. Second, it establishes R\&D infrastructure and attracts and supports enterprises towards selected industrial clustering sites according to the industrial policies of the local government. One of the roles of the DRD is to execute projects of infrastructure building according to the industrial policies established by the local government; however, sometimes, the division suggests new industries and leads the industrial policy direction to catch up with changing global trends and foster the future development of the region. Within the DRD organization, all the groups except the Daegu Advanced Manufacturing Technology Support Center and Goryeong Advanced Manufacturing Technology Support Center of the Ultimate Manufacturing R\&D Group belong to the latter. The DRD explores leading global technology areas and suggests them to the local government to help it reflect such trends in its industrial policies. Further, the division secured governmental budget in cooperation with the local government and founded the High-Tech Bearing Technology Center, applied 3D Printing Manufacturing Technology Center within the Ultimate Manufacturing R\&D Group, the Construction Equipment Technology Center within the Construction Equipment R\&D Group, Aircraft System Technology Group, and the Biomedical Manufacturing Technology Center with in the Technology Convergence R\&D Group. These sub-departments of the organization advanced in the establishment of the infrastructure for technology R\&D and introduced state-of-the-art equipment. This, in turn, has attracted various related enterprises into the region, creating new industries and contributing to reinvigorating the local economy. The R\&D activities of these groups are centered on convergence manufacturing technology. The Biomedical Manufacturing Technology Center, for example, is an area converging medical, mechatronic, and root industrial technology areas. The center supports the development and manufacturing of high-value-added medical device parts of anti-seizure property. Korea's medical device industry is largely dependent on importation for the majority of core parts, and there are hardly any manufacturing enterprises in the fields of molding and injection molding for parts manufacturing. This center attracts existing automotive or electronic manufacturing enterprises, facing 
management crisis due to sluggish economic growth, to the medical device industry to help them enter the new business areas. Further, the Gyeongsangbuk-do Province is serving the key role of forming an industrial cluster for the medical device parts industry around the free economic zone of the Yeongcheon city, which houses one of the local governments of the Gyeongsangbuk-do Province.

\section{Analysis Results of Model Effectiveness and Findings}

Table 2. Budget Introduced through Daegyeong Regional Division per Year (Based on the Analysis Results by L\&K Patent Firm)

\begin{tabular}{lcccccc}
\hline $\begin{array}{l}\text { Support fund } \\
\text { (Billion KRW) }\end{array}$ & 2009 & 2010 & 2011 & 2012 & 2013 & Total \\
\hline $\begin{array}{l}\text { Establishing } \\
\text { infrastructure }\end{array}$ & 0.35 & 1.04 & 0.74 & 6.75 & 39.25 & 48.13 \\
\hline Joint R\&D & 0.81 & 0.31 & 1.54 & 4.57 & 3.3 & 10.55 \\
\hline $\begin{array}{l}\text { Short-term } \\
\text { troubleshootin } \\
\text { g technological } \\
\text { support }\end{array}$ & 0.63 & 1.48 & 2.01 & 2.9 & 4.19 & 11.21 \\
\hline Total & 1.79 & 2.83 & 4.29 & 14.22 & 46.74 & 69.87 \\
\hline \hline
\end{tabular}

The DRD secured a total of 69.8 billion won over the five years between 2009 and 2013, and has been providing services including establishing infrastructure, joint $R \& D$ with enterprises, and short-term troubleshooting technological support. In terms of budget investment, infrastructure building accounted for the greatest investment worth 48.13 billion won over the five years (Table II). Building infrastructure indicates the cost incurred for building facilities for R\&D and enterprise support, and purchasing equipment. Built facilities include the office space for enterprises, as well as laboratories, experiment rooms, and factory areas for manufacturing technology testing. These facilities also include those for technology education for enterprises. The budget introduced to the joint R\&D with researchers and enterprises totaled 10.55 billion won over the five years. The principle of the R\&D activity of the DRD is to have joint R\&D with enterprises. For example, the division surveyed the demand of enterprises in order to select and execute projects for original industrial technology development. Short-term troubleshooting technological support is distinct from $R \& D$. This service provides intervention by experts from the headquarters to analyze and improve the technological problems often occurring in manufacturing sites. The budget invested for short-term troubleshooting technological support totaled 11.21 billion won during the five years.

Table 3. Overview of Enterprises Supported by Daegyeong Regional Division between 2009 and 2013 (Based on the Analysis Results By L\&K Patent Firm)

\begin{tabular}{lc}
\hline \hline Category & Invested amount \\
\hline Number of introduced experts & 50 \\
\hline Joint R\&D (cases of project) & 85 \\
\hline Sponsored equipment (pieces) & 70 \\
\hline $\begin{array}{l}\text { Technological problem } \\
\text { support(cases) }\end{array}$ & 1,143 \\
\hline \hline
\end{tabular}

The overview of the enterprise support realized through budget investment by the DRD showed that 50 doctors supported the 263 enterprises. Joint R\&D projects conducted totaled 85, 70 pieces of equipment were deployed, and 1,142 cases of short-term troubleshooting technological support was provided (Table 3).

The survey on the outcomes achieved through the invested budget and support was conducted with 73 
out of a total of 263 beneficiary manufacturing enterprises. Big enterprises accounted for $55.2 \%$ and SMEs $44.8 \%$. Of the total enterprises that responded, $63.9 \%$ were running independent research centers and were pursuing technology-based manufacturing in place of assembly manufacturing. Table IV shows the average figures of outcomes achieved by the enterprises after benefitting from the technological support. The figures are comparative results between the year before and after the support. The average outcome is summarized as sales increase worth 37 million won, cost reduction worth 77 million won, import-substitution effect worth 68 million won, and 2.3 newly employed persons. The sales increase and import-substitution effect are outcomes resulting from the development of specimen manufacturing technology, and cost reduction results from the improved manufacturing process. The performance following the increased sales and cost reduction effect is 1.17 billion won on average. The 73 enterprises, which make up $27.8 \%$ of the enterprises that benefitted, yielded approximately 85 billion won of economic performance, which is well over the total invested budget worth 69.8 billion won. If this were to be applied to all the 263 enterprises in practice, greater economic outcomes would have been achieved. The successful economic performances realized by those entities was possible because governmental policy, budget support, cooperation by local government, and enterprise-optimized $R \& D$ and support by research institutions were all simultaneously realized in harmony.

Table 4. Overview of Outcomes Achieved before and after Technological Support (Average per Enterprise) (Based On The Analysis Results By L\&K Patent Firm)

\begin{tabular}{ll}
\hline \hline Outcome & Average figure per enterprise \\
\hline Sales increase & $370,000,000 \mathrm{KRW}$ \\
\hline Cost reduction effect & $770,000,000 \mathrm{KRW}$ \\
\hline Import substitution & $680,000,000 \mathrm{KRW}$ \\
\hline New employment & 2.3 people \\
\hline \hline
\end{tabular}

\section{Summary}

In order to actually transfer manufacturing technologies to enterprises and implement them after development, the network of stakeholders (government-region-research institution-enterprise) is indispensable. Korea has established national industrial policies, and founded KITECH to advance its manufacturing industry. It is extremely important to establish a close relationship with industrial sites to develop and transfer manufacturing technologies that correspond with the needs of industrial sites located across the country. Therefore, KITECH has established ten local divisions and fifty centers around the country and has been actively extending support, meeting the needs of manufacturing sites. The DRD management case represents the organization and management overview of the KITECH. The following approach is required with respect to two aspects of innovation for the manufacturing infrastructure of industries. First, real manufacturing sites of enterprises based in the existing industrial clusters should be diagnosed, and manufacturing technology optimized for each individual enterprise should be developed and transferred; second, the development and transfer of manufacturing technology should be associated with the future industry, fostering policies of the central and local governments. Establishment of infrastructure for $R \& D$ and technological support around selected industrial clustering sites should be materialized first to attract diverse enterprises. In this case, research institutions are responsible for analyzing global trends and discovering new future-oriented industry areas. In reality, many of them made suggestions to the central and local governments in the process of establishing industrial policies. The DRD has been serving both roles to this day. 


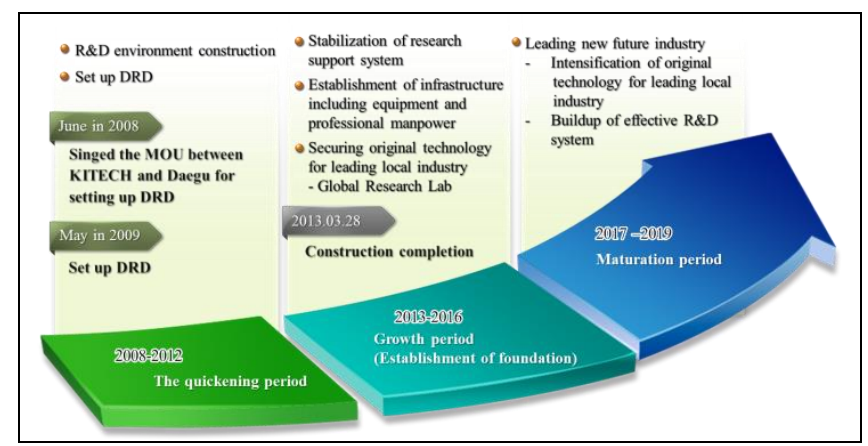

Fig. 2. Model for the transfer and implementation of manufacturing technology of the DRD.

Fig. 2 shows the past achievements and the future direction of the DRD. Since 2009 to date, the division has been establishing the infrastructure for $R \& D$ and enterprise support in accordance with the industrial policies and overview of the central and local governments, and conducting joint R\&D with and extending troubleshooting technological support to enterprises. As a result, the division has largely contributed to the sales increase, cost reduction, import substitution, and job creation of the benefitting enterprises. In addition, the division has been not only providing demand-tailored technology development and support to enterprises in order to invigorate the future growth engine in the rapidly transforming global community, but has also been working to discover new industry areas and establish the required infrastructure to attract various enterprises. Lastly, for the coming years from 2017 to 2019, the division will work harder to strengthen the infrastructure for the development and distribution of technologies related to the industrial application of artificial intelligence and smart factory based on the infrastructure and accumulated expertise established so far. Further, the division will continue to expand more concrete leading industry areas for the future.

\section{Acknowledgment}

We thank all of the respondents to the survey, from SME networks. The survey was supported by L\&K patent firm.

\section{References}

[1] Greitemann, J., et al. (2017). Technology lifecycle-oriented search for production technologies. CIRP Journal of Manufaturing Science and Technology, 16, 21-33.

[2] Laosirihongthong, T., Paul, H., \& Speece, M. W. (2003). Evaluation of new manufacturing technology implementation: an empirical study in the Thai automotive industry. Technovation, 23, 321-331.

[3] Heinze, T., \& Kuhlmann, S. (2008). Across institutional boundaries? Research collaboration in German public sector nanoscience. Research policy, 37, 888-899.

[4] Robin, S., \& Schubert, T. (2013). Cooperation with public research institutions and success in innovation: Evidence from France and Germany. Research Policy, 42, 149-166.

[5] Jia, W., Liu, L., \& Xie, X. (2010). Diffusion of technical innovation based on industry-university-institute cooperation in industrial cluster. The Journal of China Universitites of Posts and Telecommunications, 17, 45-50.

[6] Vie, O. E., Stensli, M., \& Lauvas, T. A. (2014). Increasing companies' absorptive capacity through participation in collaborative research centres. Energy Procedia, 58, 36-42.

[7] Kaiser, U., \& Kuhn, J. M. (2012). Long-run effects of public-private research joint ventures: The case of the Danish Innovation Consortia support scheme. Research Policy, 41, 913-927.

[8] Stock, G. N., \& McDermott, C. M. (2001). Organizational and strategic predictors of manufacturing 
technology implementation success: An exploratory study. Technovation, 21, 625-636.

[9] Hsu, C. W. (2005). Formation of industrial innovation mechanisms through the research institute. Technovation, 25, 1317-1329.

[10] McNie, E.C., Parris, A., \& Sarewitz, D. (2016). Improving the public value of science: A typology to inform discusstion, design and implementation of research. Research Policy, 45, 884-895.

[11] Mok, K. Y., Shen, G. Q., Yang, R. J., \& Li, C. Z. (2017). Investigation key challenges in major public engineering projects by a network-theory based analysis of stakeholder concern: A case study. International Journal of Project Management, 35, 78-94.

[12] Leven, P., Holmstrom, J., \& Mathiassen, L. (2014). Managing research and innovation networks: Evidence from a government sponsored cross-industry program. Research Policy, 43, 156-168.

[13] Brown, J. R., Martinsson, G., \& Petersen, B. C. (2017). What promotes R\&D? Comparative evidence from around the world. Research Policy, 46, 447-462.

[14] Cho, Y., Yoon, S. P., \& Kim, K. S. (2016). An industrial technology roadmap for supporting public R\&D planning. Technological Forecasting \& Social Change, 107, 1-12.

[15] Swamidass, P. M. (2003). Modeling the adoption rates of manufacturing technology innovations by small US manufacturers: a longitudinal investigation. Research Policy, 32, 351-366.

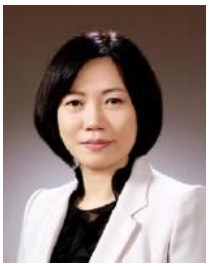

Heekyung An is a principal Researcher at Korea Institute of Industrial Technology. She received her $\mathrm{PhD}$ in global environment studies from Kyoto University in Japan in 2007. She has been in charge of planning R\&D projects and establishing strategy for advanced manufacturing technology transfer since 2008. 